\title{
Individual and Combined Effects of Food Components in Attenuating the Formation of Advanced Glycation End Products (AGEs)
}

\author{
Monisha Pradeep ${ }^{1}$, Filmon Kiflezghi Kiflemariam ${ }^{2 *}$, , Eden Tareke ${ }^{1,3}$ () \\ ${ }^{1}$ Food for Health Research Center, Lund University, Lund, Sweden \\ ${ }^{2}$ Department of Clinical Laboratory, Asmara College of Health Sciences, Asmara, Eritrea \\ ${ }^{3}$ Orotta College of Medicine and Health Science, Asmara, Eritrea \\ Email: *filmonkiflezghi.k@gmail.com
}

How to cite this paper: Pradeep, M., Kiflemariam, F.K. and Tareke, E. (2022) Individual and Combined Effects of Food Components in Attenuating the Formation of Advanced Glycation End Products (AGEs). Food and Nutrition Sciences, 13, 17-25. https://doi.org/10.4236/fns.2022.131003

Received: November 17, 2021

Accepted: January 15, 2022

Published: January 18, 2022

Copyright $\odot 2022$ by author(s) and Scientific Research Publishing Inc. This work is licensed under the Creative Commons Attribution International License (CC BY 4.0).

http://creativecommons.org/licenses/by/4.0/

\begin{abstract}
Advanced Glycation End Products (AGEs) have been associated as a possible cause in inflammation-mediated chronic diseases such as diabetes, Alzheimer's and cardiovascular disorders. Thus, inhibition of AGE formation represents a prospective therapeutic target for the prevention and treatment of these complications. This study investigated the individual and combined effects of dietary ingredients, spices, on lowering AGEs formation in meat patties. In the study, Carboxymethyllysine (CML), a well-investigated AGE is used as a marker for AGEs and malondialdehyde (MDA) as an indicator for lipid peroxidation. Nine spices were selected based on their ability to inhibit the formation of AGEs at different stages of Maillard reactions. Individually, all the 9 selected spices significantly inhibited the formation of AGEs. Among the 33 combinations of spices, 26 combinations significantly inhibited the formation of AGEs. The highest reduction (84\%) was found by the combination of Black Pepper-Rose-Cumin. The individual spices failed to significantly lower the MDA concentration; however, all 33 combinations were able to significantly reduce MDA concentration. The results of this study showed that spices when supplemented in combinations are more effective in inhibiting the formation of AGEs and in decreasing MDA concentration in meat patties.
\end{abstract}

\section{Keywords}

Advanced Glycation End-Products, CML, Spice Combinations, Malondialdehyde 


\section{Introduction}

Maillard reactions are non-enzymatic browning reactions involving nucleophilic amino groups in amino acids, peptides and proteins, and the reactive carbonyl group of reducing sugars [1]. The reactions can take place endogenously, and during heat processing of food [2]. In a simplified scheme, the Maillard reactions can be divided into three stages: initiation, propagation, and advanced stage [3]. In the initiation stage, the reducing sugar $(-\mathrm{CHO})$ couples with the amino group $\left(-\mathrm{NH}_{2}\right)$ of amino acids, proteins, and peptides to form an unstable Schiff base, which further leads to the formation of stable ketoamine derivatives known as Amadori products. These products are prone to auto-oxidation and free radical generation leading to the formation of reactive carbonyl intermediates [4]. During the propagation stage, the reactive carbonyl intermediates react with Amadori compounds, leading to the formation of Advanced Glycation End Products (AGEs) [5] such as $\mathrm{N} \varepsilon$-(1-Carboxymethyl)-L-Lysine (CML) and $\mathrm{N} \mathcal{\varepsilon}$-(1-Carboxyethyl)L-Lysine (CEL). In the advanced stage, cross-links between two lysine result in the formation of Glyoxal Lysine Dimer (GOLD) and Methylglyoxal Lysine Dimer (MOLD), and the cross-link between lysine and arginine forms glucosepane and pentosidine [6]. Though AGEs is a collective name of a wide range of Maillard reactions, CML, the most studied AGE, is used as a marker for AGE formation [7].

Maillard reaction products, both from endogenous and exogenous are also implicated in the development of oxidative stress, inflammation, and age-related chronic conditions such as diabetes mellitus, atherosclerosis, and Alzheimer's [8] [9]. Thus, the importance of restricted exposure to AGEs from exogenous (from processed food) as well as endogenous sources has been focused on, as a way of prevention. Pharmaceutical drugs such as aminoguanidine, metformin, pyridoxamine, carnosine, and others have therefore been tested to inhibit the endogenous formation of AGEs, as a way of preventing the risk for adverse health complications. However, even though several potential drugs were identified many times, undesirable side effects have limited their utilization [10]. Thus, natural food-based anti-AGEs are being investigated and many natural products and spices have been proven to inhibit the formation of AGEs at the different stages of Maillard reactions. However, the use of dietary components to inhibit AGE formation is limited by the fact that they are not consumed in pharmaceutical concentrations.

Therefore, this study aims to investigate and compare the effect of spices in single and combined forms for possible enhanced combined/supplementary effects in inhibiting AGEs formation during heating of meat patties.

\section{Materials and Methods}

\subsection{Materials}

Carboxymethyl Lysine-d4 (d4-CML), CML, was purchased from Larodan Fine Chemicals AB (Malmö Sweden). Ammonium hydroxide solution (25\%), Trichlo- 
roacetic Acid (TCA), and hydrochloric acid were purchased from Merck (Darmstadt, Germany). Methanol (HPLC grade) was provided by Scharlau (Barcelona, Spain). Sodium borohydride, Nonafluoropentanoic Acid (NFPA, 97\%), 2-Thiobarbituric Acid (TBA) and Butylated Hydroxytoluene (BHT) were purchased from Sigma-Aldrich (Steinheim, Germany). Solid-Phase Extraction (SPE) columns TELOS neo (PCX 200 mg, 6 mL) were purchased from Sorbent AB (Västra Frölunda, Sweden). Minced meat, (all from one batch, $50 \%$ pork and 50\% beef containing $15 \%$ fat and $18 \%$ protein) and the spices cinnamon, cumin, thyme, garlic, rose petals, turmeric, black pepper, rosemary and clove were purchased from Swedish local market ICA Malmborgs Tuna (Lund, Sweden). All organic solvents are of analytical grade and all aqueous solutions were prepared using Milli-Q water (Millipore SA, Molsheim, France).

\subsection{Preparation of Meat Patties}

The meat patties were prepared in the laboratory kitchen of the Food for Health Science center, Lund University. Minced meat (15 g) and homogenized individual and combined spices $(20 \mathrm{mg}$ ) were pressed in a circular plastic box, $6 \mathrm{~cm} \times 6$ $\mathrm{cm} \times 0.5 \mathrm{~cm}$. Meat patties, a batch of four at a time, were then evenly heated at $175^{\circ} \mathrm{C}$ for 1 minute on each side in a preheated pan. After removing the patties, the pan was also allowed to cool down for 10 minutes and the same procedure was followed for the consecutive group of meat patties and meat patties without spices served as control.

\subsection{Standardization of Preparation Method}

Control meat patties were prepared in triplicate in three consecutive days. Concentrations of CML and weight loss were determined as a way of standardizing the preparation method. The ground spices clove, cinnamon, cumin, garlic, thyme, turmeric, rose petals, rosemary, and black pepper were used in the study. Spices were first clustered into three groups based on the stage in which they inhibit the reaction based on previous studies [11]-[20]. A spice from each group was then used to make 33 different combinations to be added to the meat patties. Control meat patties, meat patties with the 9 individual spices ( $20 \mathrm{mg}$ of each spice), and patties with combined spices (33 different combinations, $20 \mathrm{mg}$ of each combined spice) were homogenized and prepared in triplicate. The samples were then kept in a $-18^{\circ} \mathrm{C}$ freezer until further analysis.

\subsection{Sample Preparation for LC-MS/MS Analysis}

Meat patties were thawed at room temperature for 30 minutes and mixed before taking triplicate samples. The sample preparation was carried out according to the protocol of [21] [22], with minor modifications. The samples were defatted twice using $1 \mathrm{ml}$ of hexane and dried under a stream of nitrogen gas. Sodium tetraborate $(1 \mathrm{ml}, 0.1 \mathrm{M})$ followed by $1 \mathrm{ml}$ of sodium borohydride $(0.1 \mathrm{M}$ in 0.2 $\mathrm{M} \mathrm{NaOH}$ ) was added for Schiff base reduction. The samples were incubated at 
$4^{\circ} \mathrm{C}$ for 6 hours to obtain optimal reduction. After 6 hours, $60 \%$ TCA was added to precipitate the protein. The samples were then centrifuged at $3500 \mathrm{rpm}$ for 15 minutes and the precipitate was washed with $500 \mu \mathrm{l} 60 \%$ TCA (3500 rpm for 20 minutes). An internal standard, d4-CML ( $40 \mu \mathrm{g} / \mathrm{g}$ sample) was added to the precipitate before incubation with $6 \mathrm{M} \mathrm{HCl}$ at $110^{\circ} \mathrm{C}$ for 24 hours. After incubation, the $\mathrm{HCl}$ was evaporated to dryness under a stream of nitrogen gas. The CML was then extracted using SPE, dried, and reconstituted in $200 \mu \mathrm{l} 25 \mathrm{mM}$ NFPA in $\mathrm{H}_{2} \mathrm{O}$ and analyzed using LC-MS/MS.

\subsection{Quantification of Total CML by LC-MS/MS}

The quantification of CML was performed using High-Pressure Liquid Chromatography/Mass Spectrometry (HPLC-MS/MS). Instruments used were Accela UHPLC pump with auto-injector coupled to LTQ Velos Pro Orbitrap mass-spectrometer (Thermo Scientific, Waltham, USA). For data quantification and evaluation, XcaliburTM 2.2 software (Thermo Scientific) was used. The MS/MS was run in positive electrospray ionization ion trap mode, detecting two Selected Reaction Monitoring (SRM) transitions for CML as well as two SRM for corresponding internal standard. Solid-phase extraction, chromatographic parameters, ion source parameter, and the SRM transitions are the same as described by [22]. The calibration curve was prepared with $0,1,2.5,10,50,100$ and $500 \mu \mathrm{g} / \mathrm{ml} \mathrm{CML}$ and CEL with fixed amounts, $100 \mu \mathrm{g} / \mathrm{ml}$, of d4-CML. Samples containing higher than the highest concentration of CML in the calibration curve were diluted to fit into the curve.

\subsection{Sample Preparation for MDA Analysis}

A Thiobarbituric acid test, adapted from [23], with modifications was used for the analysis of MDA concentrations in the patties. Meat patty $(1 \mathrm{~g})$ was weighed and transferred into $25 \mathrm{ml}$ centrifuge Falcon tubes. Aqueous TCA (10\%, $4 \mathrm{ml}$ of) and BHT $(0.8 \%, 2.5 \mathrm{ml})$ were added successively. The contents were mixed well for 30 seconds and centrifuged for 3 minutes at $3000 \mathrm{rpm}$. The bottom aqueous layer was made to $10 \mathrm{~mL}$ volume with $10 \% \mathrm{TCA}$, and a $2.5 \mathrm{~mL}$ was pipetted into a tube to which a $1.5 \mathrm{~mL}$ of $0.8 \%$ aqueous TBA was added and incubated at $70^{\circ} \mathrm{C}$ for 30 minutes. After incubation, the tubes were allowed to cool by placing them in a cold-water bath to reach room temperature. The MDA concentrations were estimated by measuring the absorbance at $540 \mathrm{~nm}$ using a spectrophotometer. The MDA concentration for the meat patties was calculated using the calibration curve and the results were expressed in $\mathrm{ng} / \mathrm{ml}$.

\subsection{Data Analysis}

The results are presented as mean \pm standard deviation. Statistical analysis was carried out by using one-way ANOVA followed by LSD post hoc test by using SPSS statistical software (version 22). Differences were considered to be significant at $\mathrm{P}<0.05$ and at $\mathrm{P}<0.01$. 


\section{Results and Discussion}

The study investigated the individual and combined effect of dietary ingredients, spices, on lowering AGEs formation in meat patties.

The Relative Standard Deviation (RSD) for weight loss upon heating, reflecting evaporation of water in control patties was less than $5 \%$. The average weight loss on all 3 days was $32.82 \% \pm 2.26 \%$ and there was no significant difference in the diameter and thickness of the heated meat patties (Table 1). No significant difference was observed on CML between the control patties that were analyzed at $\mathrm{t}=0$ and $\mathrm{t}=180$ days stored at $-18^{\circ} \mathrm{C}$.

The concentration of CML measured in all the meat patties treated with nine different spices as depicted in Figure 1 shows that meat patties treated with all the nine individual spices (black pepper (Bp), cinnamon (Ci), cumin $(\mathrm{Cu})$, thyme $(\mathrm{Th})$, turmeric $(\mathrm{Tu})$, rose $(\mathrm{Ro})$, rosemary $(\mathrm{Rm})$, clove $(\mathrm{Cl})$ and garlic $(\mathrm{Ga})$ ) showed a significant decrease in CML concentrations. Black pepper and thyme showed the highest decrease in CML concentration into $69.7 \%$ and $65.4 \%$ respectively compared to control.

When combined, 26 of the overall 33 spice combinations significantly reduced the CML concentration with respect to control. Figure 2 displays the effect of all the spice combinations on CML concentration compared to the control. The decrease in the CML concentrations by the spice combinations ranged from $46.4 \%$ in patties supplemented with $\mathrm{Cl}-\mathrm{Ci}-\mathrm{Cu}$ to $84 \%$ for patties supplemented with $\mathrm{Bp}-\mathrm{Ro}-\mathrm{Cu}$. The study shows that the concentration of CML inhibition was higher when the spices were combined. These results are in line with the previous studies by [24] [25], where the authors suggest that combinations of $\mathrm{Tu}$ and $\mathrm{Bp}$ and $\mathrm{Ci}$ and $\mathrm{Cl}$ have a better effect of AGE inhibition than when used individually.

Spice combination of Bp-Ci-Th, Bp-Ro-Th, Ga-Ci-Cu, Ga-Ci-Tu, Ga-Ro-Tu, Ga-Ro-Rm, and Ga-Tu-Cu, despite showing potent activity individually, failed to reduce $\mathrm{CML}$ concentration significantly which could be due to the antagonistic nature of the interaction of the spices when combined.

In this study, MDA was used as an indicator for lipid peroxidation. There was no significant effect of all the individual spices on the MDA concentration compared to control. However, combined spices lead to a more pronounced effect in reducing MDA concentrations compared to individual spices. As shown in Figure 3 all the spice combinations significantly reduced the MDA concentration. The reduction of MDA concentrations by spice combinations ranged from $34.2 \%$ in Ga-Ro-Tu to $86.2 \%$ in Cl-Ci-Th.

Table 1. Weight loss analysis for control samples in three consecutive days $(n=32)$.

\begin{tabular}{cccccccc}
\hline $\begin{array}{c}\text { Weight } \\
\text { loss analysis }\end{array}$ & $\begin{array}{c}\text { Initial weight } \\
(\mathbf{g})\end{array}$ & $\begin{array}{c}\text { Final weight } \\
(\mathbf{g})\end{array}$ & $\begin{array}{c}\text { Length } \\
(\mathbf{c m})\end{array}$ & $\begin{array}{c}\text { Breadth } \\
(\mathbf{c m})\end{array}$ & $\begin{array}{c}\text { Width } \\
(\mathbf{c m})\end{array}$ & $\begin{array}{c}\text { Weight loss } \\
(\%)\end{array}$ & $\begin{array}{c}\text { RSD } \\
(\%)\end{array}$ \\
\hline Day 1 average & 15 & $9.86 \pm 0.37$ & $4.7 \pm 0.25$ & $4.3 \pm 0.28$ & $0.3 \pm 0.08$ & $34.27 \pm 2.46 \%$ & 3.75 \\
Day 2 average & 15 & $10.61 \pm 0.29$ & $4.8 \pm 0.20$ & $4.5 \pm 0.19$ & $0.3 \pm 0.06$ & $29.27 \pm 1.93 \%$ & 2.73 \\
Day 3 average & 15 & $9.76 \pm 0.37$ & $4.7 \pm 0.18$ & $4.4 \pm 0.20$ & $0.3 \pm 0.06$ & $34.93 \pm 2.46 \%$ & 3.79 \\
Total average & 15 & $10.08 \pm 0.34$ & $4.73 \pm 0.21$ & $4.4 \pm 0.22$ & $0.3 \pm 0.06$ & $32.82 \pm 2.26 \%$ & 3.43 \\
\hline
\end{tabular}




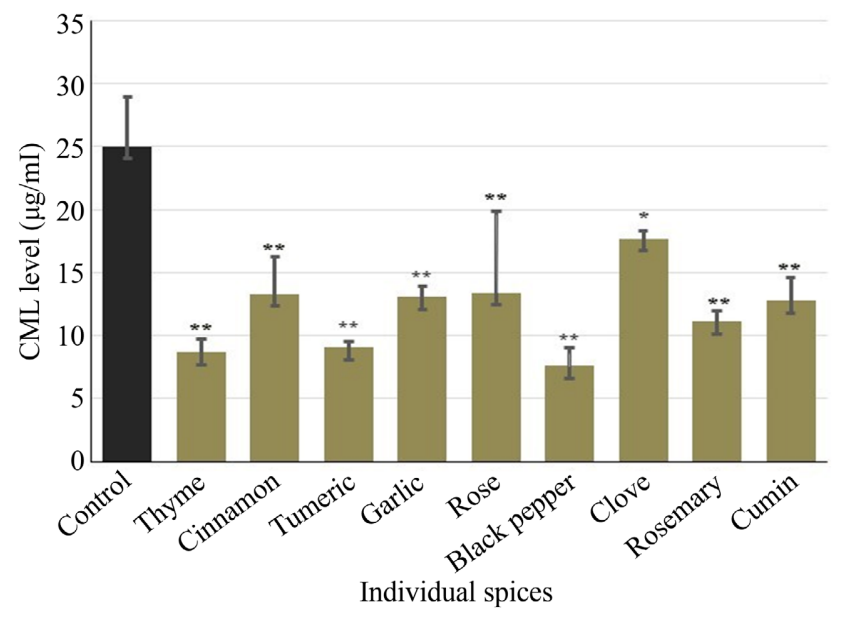

Figure 1. Effect of individual spices in reduction of CML concentration. Results are expressed as mean $\pm \mathrm{SD} .{ }^{* *}$ indicates highly significant values with $\mathrm{P}$ value $<0.01$.

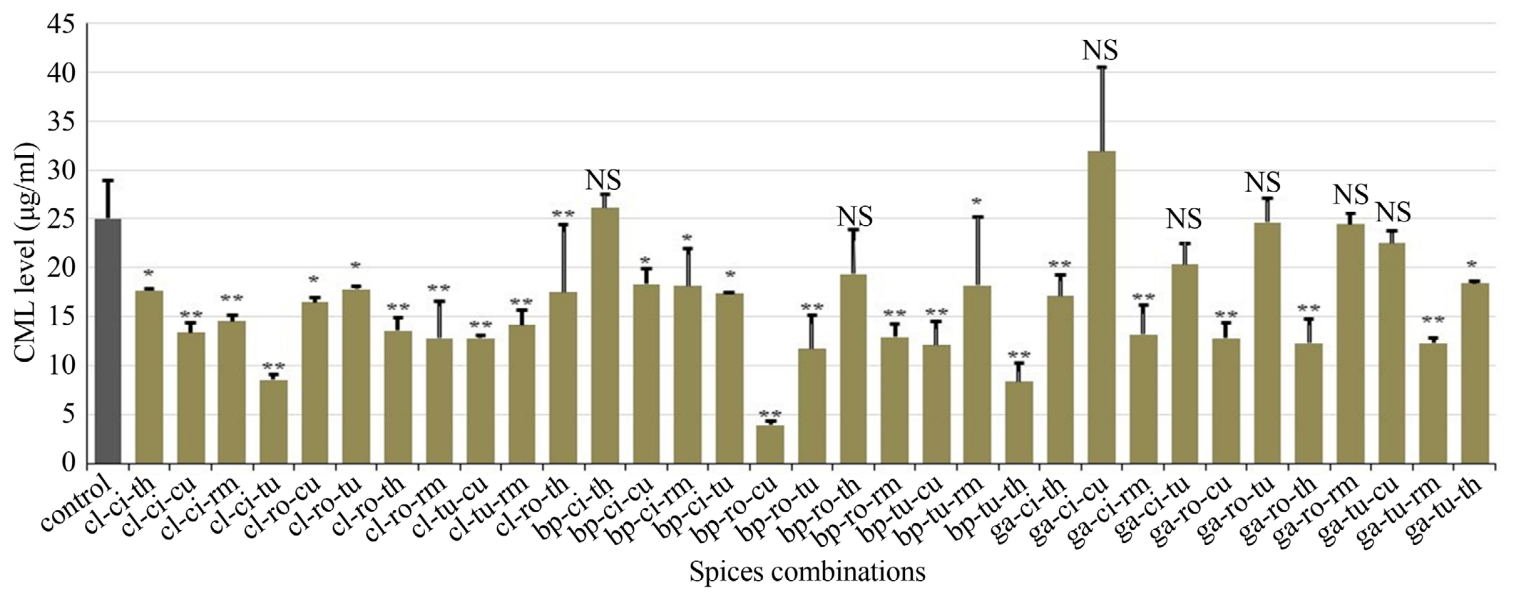

Figure 2. The Effect of all spice combination on CML concentration. ${ }^{\star}$ and ${ }^{\star *}$ indicates significant reduction at $\mathrm{P}$ value of less than 0.05 and 0.01 respectively. Results are expressed as mean \pm SD. Abbreviations: Black pepper (Bp), Cinnamon (Ci), Cumin $(\mathrm{Cu})$, Clove (Cl), Garlic (Ga) Turmeric (Tu), Thyme (Th), Rosemary (Rm) and Rose petals (Ro).

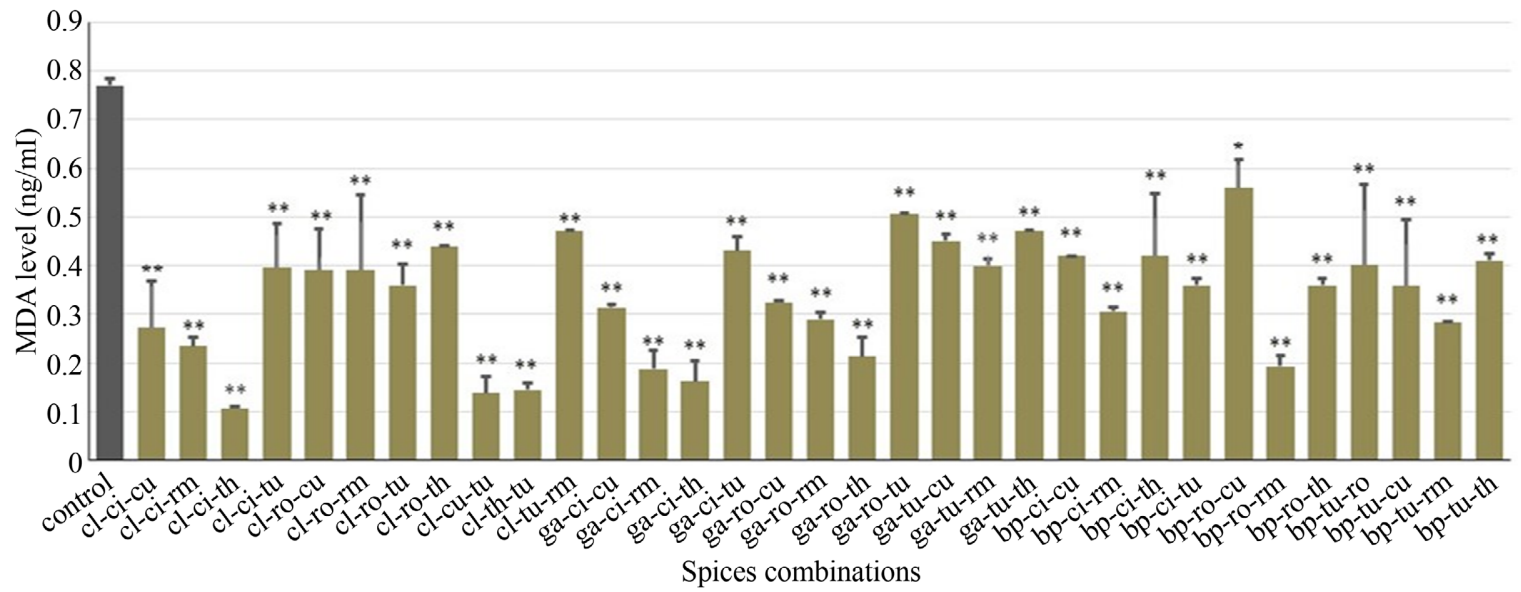

Figure 3. Spice combination that shows significant reduction of MDA concentration. ${ }^{\star}$ indicates significance at a $\mathrm{P}$-value $<0.05$. Results are expressed as mean \pm SD. Abbreviations: Black pepper (Bp), Cinnamon (Ci), Cumin (Cu), Clove (Cl), Garlic (Ga) Turmeric ( Tu), Thyme (Th), Rosemary (Rm) and Rose petals (Ro). 
Since, none of the individual spices showed statistical significance in lowering MDA concentrations, the effect of the 33 combinations that showed a significant decrease could indicate an additive or synergistic effect. It has to be noted that the TBA method for measuring MDA is not selective, thus, the results in the study can only give indications. In the study all the nine individual spices which successfully reduced CML concentration failed to significantly reduce the MDA concentration. When combined, seven combinations were unable to significantly reduce the CML concentration while all the combinations were able to reduce the MDA concentration significantly. Thus, more studies are needed to explore the correlation between MDA and CML formation with respect to individual and combined spices in meat patties. Further research in understanding the role of active dietary components in inhibition of AGEs formation and lipid peroxidation may help in the selection of natural products for decreasing AGEs and lipid peroxidation formation and consequently in the prevention of adverse health effects associated with AGEs and lipid peroxidation.

\section{Conclusion}

In conclusion, the results of this study support the hypotheses that spices when added in combinations could effectively reduce the concentration of CML levels and MDA concentrations formed in heated meat patties. This study could be used as a basis for studying the effects of individual and combined spices on the endogenous formation of AGEs and associated health effects. Moreover, this study calls for investigations to clarify the association between the total formation of AGEs and lipid peroxidation. This study has also incited the need to study the combined effect and the nature of the interaction of different food components in the inhibition of AGEs formation.

\section{Fund}

This research was funded by the Antidiabetic Food Center (AFC), a VINN Excellence Center funded by VINNOVA at Lund University, and the Direktör Albert Påhlsson Foundation.

\section{Conflicts of Interest}

The authors declare no conflicts of interest concerning the research or its funding.

\section{References}

[1] Hodge, J.E. (1953) Dehydrated Foods, Chemistry of Browning Reactions in Model Systems. Journal of Agricultural and Food Chemistry, 1, 928-943. https://doi.org/10.1021/jf60015a004

[2] Powrie, W.D., Wu, C.H. and Molund, V.P. (1986) Browning Reaction Systems as Sources of Mutagens and Antimutagens. Environmental Health Perspectives, 67, 47-54. https://doi.org/10.1289/ehp.866747

[3] Wu, C.H., Huang, S.-M., Lin, J.-A. and Yen, G.-C. (2011) Inhibition of Advanced 
Glycation End Products Formation by Foodstuffs. Food \& Function, 2, 224-234. https://doi.org/10.1039/c1fo10026b

[4] Bastos, D.M., Siguemoto, E. and Sefora, M. (2012) Maillard Reactions Products in Processed Food: Pros and Cons. In: Valdez, B., Ed., Food Industrial Processes: Method and Equipments, IntechOpen, London, 281-300.

[5] Vistoli, G., De Maddis, D., Cipak, A., Zarkovic, N., Carini, M. and Aldini, G. (2013) Advanced Glycoxidation and Lipoxidation End Products (AGEs and ALEs): An Overview of Their Mechanism of Formation. Free Radical Research, 47, 3-27. https://doi.org/10.3109/10715762.2013.815348

[6] Chuyen, N.V. (2006) Toxicity of the AGEs Generated from the Maillard Reaction: on the Relationship of Food-AGEs and Biological-AGEs. Molecular Nutrition \& Food Research, 50, 1140-1149. https://doi.org/10.1002/mnfr.200600144

[7] Srey, C., Hull, G.L.J., Connolly, L., Elliott, C.T., del Castillo, M.D. and Ames, J.M. (2010) Effect of Inhibitor Compounds on $N^{\varepsilon}$-(Carboxymethyl)lysine (CML) and $N^{\varepsilon}$ (Carboxyethyl)lysine (CEL) Formation in Model Foods. Journal of Agricultural and Food Chemistry, 58, 12036-12041. https://doi.org/10.1021/jf103353e

[8] Nass, N., Bartling, B., Santos, A.N., Scheubel, R.J., Börgermann, J., Silber, R.E., et al. (2007) Advanced Glycation End Products, Diabetes and Ageing. Zeitschrift für Gerontologie und Geriatrie, 40, 349-356. https://doi.org/10.1007/s00391-007-0484-9

[9] Poulsen, M.W., Hedegaard, R.V., Andersen, J.M., de Courten, B., Bügel, S., Nielsen J., et al. (2013) Advanced Glycation End Products in Food and Their Effects on Health. Food and Chemical Toxicology, 60, 10-37. https://doi.org/10.1016/j.fct.2013.06.052

[10] Reddy, V.P. and Beyaz, A. (2006) Inhibitors of the Maillard Reaction and AGE Breakers as Therapeutics for Multiple Diseases. Drug Discovery Today, 11, 646-654. https://doi.org/10.1016/j.drudis.2006.05.016

[11] Ahmad, M.S. and Ahmed, N. (2006) Antiglycation Properties of Aged Garlic Extract: Possible Role in Prevention of Diabetic Complications. The Journal of Nutrition, 136, 796S-799S. https://doi.org/10.1093/jn/136.3.796S

[12] Dearlove, R.P., Greenspan, P., Hartle, D.K., Swanson, R.B. and Hargrove, J.L. (2008) Inhibition of Protein Glycation by Extracts of Culinary Herbs and Spices. Journal of Medicinal Food, 11, 275-281. https://doi.org/10.1089/jmf.2007.536

[13] Ho, S.-C., Chang, P.-W., Tong, H.-T. and Yu, P.-Y. (2014) Inhibition of Fluorescent Advanced Glycation End-Products and N-Carboxymethyllysine Formation by Several Floral Herbal Infusions. International Journal of Food Properties, 17, 617-628. https://doi.org/10.1080/10942912.2012.654566

[14] Hsieh, C.L., Peng, C.H., Chyau, C.C., Lin, Y.C., Wang, H.E. and Peng, R.Y. (2007) Low-Density Lipoprotein, Collagen, and Thrombin Models Reveal that Rosemarinus officinalis L. Exhibits Potent Antiglycative Effects. Journal of Agricultural and Food Chemistry, 55, 2884-2891. https://doi.org/10.1021/jf0631833

[15] Joglekar, M.M., Panaskar, S.N. and Arvindekar, A.U. (2014) Inhibition of Advanced Glycation End Product Formation by Cymene-A Common Food Constituent. Journal of Functional Foods, 6, 107-115. https://doi.org/10.1016/j.jff.2013.09.024

[16] Morimitsu, Y., Yoshida, K., Esaki, S. and Hirota, A. (1995) Protein Glycation Inhibitors from Thyme (Thymus vulgaris). Bioscience, Biotechnology, and Biochemistry, 59, 2018-2021. https://doi.org/10.1271/bbb.59.2018

[17] Peng, X., Cheng, K.W., Ma, J., Chen, B., Ho, C.T., Lo, C., et al. (2008) Cinnamon Bark Proanthocyanidins as Reactive Carbonyl Scavengers to Prevent the Formation of Advanced Glycation Endproducts. Journal of Agricultural and Food Chemistry, 56, 1907-1911. https://doi.org/10.1021/jf073065v 
[18] Bosca, A.R., Gutierrez, M.A.C., Soler, A., Puerta, C., Diez, A., Quintanilla, E., et al. (1997) Effects of the Antioxidant Turmeric on Lipoprotein Peroxides: Implications for the Prevention of Atherosclerosis. Age, 20, 165-168.

https://doi.org/10.1007/s11357-997-0015-Z

[19] Sajithlal, G.B., Chithra, P. and Chandrakasan, G. (1998) Effect of Curcumin on the Advanced Glycation and Cross-Linking of Collagen in Diabetic Rats. Biochemical Pharmacology, 56, 1607-1614. https://doi.org/10.1016/S0006-2952(98)00237-8

[20] Suantawee, T., Wesarachanon, K., Anantsuphasak, K., Daenphetploy, T., Thien-Ngern, S., Thilavech, T., et al. (2015) Protein Glycation Inhibitory Activity and Antioxidant Capacity of Clove Extract. Journal of Food Science and Technology, 52, 3843-3850. https://doi.org/10.1007/s13197-014-1452-1

[21] He, J., Zeng, M., Zheng, Z., He, Z. and Chen, J. (2014) Simultaneous Determination of $N^{\varepsilon}$-(Carboxymethyl)lysine and $N^{\varepsilon}$-(Carboxyethyl)lysine in Cereal Foods by LCMS/MS. European Food Research and Technology, 238, 367-374. https://doi.org/10.1007/s00217-013-2085-8

[22] Tareke, E., Forslund, A., Lindh, C.H., Fahlgren, C. and Östman, E. (2013) Isotope

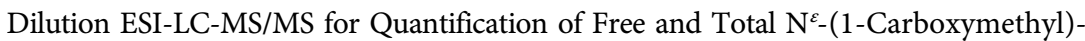
L-Lysine and Free $N^{\varepsilon}$-(1-Carboxyethyl)-L-Lysine: Comparison of Total $N^{\varepsilon}$-(1-Carboxymethyl)-L-Lysine Levels Measured with New Method to ELISA Assay in Gruel Samples. Food Chemistry, 141, 4253-4259.

https://doi.org/10.1016/j.foodchem.2013.07.003

[23] Botsoglou, N.A., Fletouris, D.J., Papageorgiou, G.E., Vassilopoulos, V.N., Mantis, A.J. and Trakatellis, A.G. (1994) Rapid, Sensitive, and Specific Thiobarbituric Acid Method for Measuring Lipid Peroxidation in Animal Tissue, Food, and Feedstuff Samples. Journal of Agricultural and Food Chemistry, 42, 1931-1937. https://doi.org/10.1021/jf00045a019

[24] Jin, S. and Cho, K.H. (2011) Water Extracts of Cinnamon and Clove Exhibits Potent Inhibition of Protein Glycation and Anti-Atherosclerotic Activity In Vitro and In Vivo Hypolipidemic Activity in Zebrafish. Food and Chemical Toxicology, 49, 1521-1529. https://doi.org/10.1016/j.fct.2011.03.043

[25] Zhang, Y., Henning, S.M., Lee, R.P., Huang, J., Zerlin, A., Li, Z., et al. (2015) Turmeric and Black Pepper Spices Decrease Lipid Peroxidation in Meat Patties during Cooking. International Journal of Food Sciences and Nutrition, 66, 260-265. https://doi.org/10.3109/09637486.2014.1000837 